\title{
Bias in aging feral horses
}

\author{
ROBERT A. GARROTT
}

\begin{abstract}
Several investigators studying feral horses (Equus caballus) in the western U.S. have noted anomalies in the age distribution of captured horses that raised concern about the accuracy of aging technique. Possible biases in the aging technique were investigated by assembling records for 60,116 horses removed from public lands in Nevada, Oregon, and Wyoming between 1975 and 1987. Records were consolidated for each state and the resulting age distributions were compared to an expected distribution derived from a population model based on published demographic parameters. These comparisons revealed a tendency for 5-year-olds to be under represented while 6- and 7-year-olds were over represented. There were also higher than expected numbers of horses aged as 15 and 20 years. These apparent anomalies were consistent among states and also among years within each state. The pervasiveness of the trends demonstrates that several biases exist in the current aging technique. Given these uncertainties, it is recommended that development of age-specific demographic variables based on yearly increments beyond age 3 or 4 be avoided, instead lumping data into broad age classes whenever possible.
\end{abstract}

Key Words: age structure, aging techniques, demography, Equus caballus

Controversy about management of feral horses (Equus caballus) occupying public lands in the western United States has stimulated studies of many demographic parameters based on age-specific data (National Research Council 1980, Wolfe 1980, Seal and Plotka 1983, Berger 1986, Siniff et al. 1986, Plotka et al. 1988, Garrott and Taylor 1990). Two of these studies reported data on age structure (National Research Council 1980, Wolfe 1980) and both detected anomalies that raised concern about the accuracy of age estimates (National Research Council 1982). Techniques for estimating age of animals may be subject to random error (measurement and sampling), systematic bias, or a combination of both. Depending on how age data are used, such errors can have significant affects on estimation of demographic parameters (Cooke and de la Mare 1983, de la Mare and Cooke 1984), hence, careful evaluation of aging techniques is important.

Accuracy of aging techniques cannot be assessed without known-age animals (Dapson 1980); however, if age distributions are similar among populations, systematic biases may be detected by aging a large number of animals and examining the resulting age distributions (Fatti et al. 1980). Garrott et al. (1991b) reported similar demographic characteristics and growth rates for a variety of feral horse populations throughout the western United States, suggesting examination of age distributions may be useful for assessing possible bias in techniques used to estimate age of feral horses. The objective of this paper is to present the results of such a study using age distribution derived from horses captured by the Bureau of Land Management (BLM) over a 12-year period.

\section{Methods}

Records for 60,116 horses removed from public lands between 1975 and 1987 were obtained from BLM offices in Nevada,

\footnotetext{
Author is post-doctoral associate, Department of Ecology, Evolution, and Behavior, University of Minnesota, Minneapolis 55455.

Funding was provided by BLM contract USDI-AA852-CT5-29. The author wishes to thank D.B. Siniff, J.R. Tester, A.M. Starfield, and T.C. Eagle for assistance and editorial suggestions and the many BLM employees who provided data.

Manuscript accepted 6 April 1991.
}

Oregon, and Wyoming. Animals were captured using helicopters to locate and herd bands of horses into corral traps. Captured horses were transported to centralized processing facilities in each state. Each animal was restrained in a padded squeeze chute and aged by veterinarians or experienced BLM personnel using standardized dental criteria (Amer. Assoc. Equine Practitioners 1981). Eruption sequences of incisors were used to determine age through 5 years, when the last permanent incisors are fully erupted. Estimating ages beyond 5 years was more subjective because it relied on various characteristics of tooth wear and form. Horses were aged to the nearest year except in Wyoming, where no attempt was made to estimate the age of animals $\geq 12$ years old.

In order to assess possible aging bias, I compared the age distributions constructed from the data to an expected distribution derived from the demographic studies of Garrott et al. (1991b). Eberhardt et al. (1982) and Garrott et al. (1991b) provide evidence that many feral horse populations were growing at a relatively constant rate during the period when the age data were collected. The results suggest that survival and fecundity also remained relatively uniform, which would result in a stationary age structure (Caughley 1977). Garrott et al. (1991b) developed age-specific survival and fecundity schedules using the equations of Siler (1979) and Eberhardt (1985) and several sources of data. These schedules were combined in a variant of a Leslie matrix population model described by Garrott (1991) to calculate the stable age distributions (Starfield and Bleloch 1986). Age distributions were calculated for all 16 combinations of the 4 survival and 4 fecundity schedules presented by Garrott et al. (1991b). Of the 8 schedules presented by Garrott et al. (1991b), only the S1 survival schedule and the F1 and F2 fecundity schedules were developed from data. For the purpose of generating an expected age distribution for comparison with the observed age distributions presented in this paper, I chose to use the $S 1$ survival and $F 2$ fecundity schedules because they represent the most extensive data yet published. The S1 schedule was produced from survival data where all horses in a small Montana population were individually known and their fate followed for an 11-year period (Garrott and Taylor 1990). The F2 fecundity schedule was developed from the lactation status of 1,144 mares captured in June during 3 consecutive years from a herd in Nevada (Garrott et al. 1991a).

Statistical comparisons between the observed and expected age distributions were made by constructing a 2 by 11 contingency table for each state. Only the first 11 age classes $(0-10$ years) were used in the tests in order to reduce the influence of sampling variation due to the relatively small number of horses assigned to older age classes. The chi-square statistic was used to test for departures from the expected age distribution.

\section{Results}

Age distributons from all 3 states had a variety of peaks and troughs that deviated from the expected smooth distribution (Table 1). With the exception of an apparent under representation of yearlings in data from Oregon, number of horses assigned to each age class from foal to 5 years steadily decreased, as expected. Because the low proportion of yearlings was unique to data from Oregon, it cannot be attributed to aging criteria, but must represent a problem peculiar to that state.

At 5 years of age when the aging criteria switch from incisor 
Table 1. The age distribution of feral horses removed from public lands in Nevada, Oregon, and Wyoming between 1975 and 1987 and the expected stable age distribution derived from the S1 survival and F2 fecundity schedules presented by Garrott et al. (1991).

\begin{tabular}{|c|c|c|c|c|c|c|c|}
\hline \multirow[b]{3}{*}{ Age $(y r)$} & \multirow{3}{*}{$\frac{\text { Expected }}{\text { Percent }}$} & \multicolumn{6}{|c|}{ Observed } \\
\hline & & \multicolumn{2}{|c|}{ Nevada } & \multicolumn{2}{|c|}{ Oregon } & \multicolumn{2}{|c|}{ Wyoming } \\
\hline & & $\mathbf{N}$ & Percent & $\mathbf{N}$ & Percent & $\mathbf{N}$ & Percent \\
\hline 0 & 19.95 & $5993^{* *}$ & 17.88 & $1881^{* *}$ & 20.27 & $2948^{* *}$ & 17.03 \\
\hline 1 & 15.44 & 5092 & 15.19 & 960 & 10.34 & 2747 & 15.87 \\
\hline 2 & 12.52 & 4140 & 12.35 & 1393 & 15.01 & 2614 & 15.10 \\
\hline 3 & 10.16 & 3096 & 9.24 & 928 & 10.00 & 1559 & 9.00 \\
\hline 4 & 8.24 & 2485 & 7.41 & 741 & 7.98 & 1495 & 8.63 \\
\hline 5 & 6.69 & 1806 & 5.39 & 504 & 5.43 & 646 & 3.73 \\
\hline 6 & 5.42 & 3098 & 9.24 & 765 & 8.24 & 759 & 4.38 \\
\hline 7 & 4.39 & 2325 & 6.94 & 598 & 6.44 & 914 & 5.28 \\
\hline 8 & 3.56 & 1375 & 4.10 & 389 & 4.19 & 802 & 4.63 \\
\hline 9 & 2.88 & 558 & 1.66 & 213 & 2.30 & 536 & 3.10 \\
\hline 10 & 2.33 & 514 & 1.53 & 284 & 3.06 & 393 & 2.27 \\
\hline 11 & 1.88 & 251 & 0.75 & 203 & 2.19 & 375 & 2.17 \\
\hline 12 & 1.52 & 493 & 1.47 & 82 & 0.88 & & \\
\hline 13 & 1.22 & 452 & 1.35 & 16 & 0.17 & & \\
\hline 14 & 0.97 & 203 & 0.61 & 56 & 0.60 & & \\
\hline 15 & 0.77 & 343 & 1.02 & 113 & 1.22 & & \\
\hline 16 & 0.61 & 116 & 0.35 & 16 & 0.17 & & \\
\hline 17 & 0.47 & 136 & 0.41 & 2 & 0.02 & & \\
\hline 18 & 0.35 & 160 & 0.48 & 10 & 0.11 & & \\
\hline 19 & 0.25 & 31 & 0.09 & 33 & 0.36 & & \\
\hline 20 & 0.17 & 483 & 1.44 & 80 & 0.86 & & \\
\hline 21 & 0.10 & 31 & 0.09 & 0 & 0.00 & & \\
\hline 22 & 0.05 & 39 & 0.12 & 1 & 0.01 & & \\
\hline 23 & 0.02 & 41 & 0.12 & 1 & 0.01 & & \\
\hline 24 & 0.01 & 57 & 0.17 & 4 & 0.04 & & \\
\hline 25 & 0.00 & 79 & 0.24 & 6 & 0.06 & & \\
\hline$>25$ & & 106 & 0.32 & 2 & 0.02 & & \\
\hline Total & & 33521 & & 9281 & & 17314 & \\
\hline
\end{tabular}

**Tests of expected vs. observed distribution for ages $0-10$ within each state significant at the 0.01 level.

eruption to wear characteristics, age structures from all 3 states deviate from the expected smooth distribution, with the proportion of horses classified as 6-and 7-year-olds exceeding the proportion classified as 5-year-olds (Table 1). Deviations from the expected age distribution in the 5-7 year age classes were responsible for 50 to $78 \%$ of the overall chi-square statistic for each state. If these anomalies were the result of abnormally high recruitment for several years throughout western populations, then the strong cohorts should move through the population with time. Examination of the age distributions of horses captured in consecutive years, however, demonstrates that the peak in 6-7 year olds remained stationary (Fig. 1), suggesting a systematic bias in the aging technique.

The age distributions beyond 9 years old are erratic and show a strong bias toward multiples of 5 . This bias is particularly noticeable for the 15-and 20-year age classes, but is also evident to a lesser extent in the 10- and 25-year age classes (Table 1).

\section{Discussion}

The National Research Council (1980) noted under representation of yearlings in age distributions of horses derived primarily from Oregon BLM data and attributed the problem to sampling bias (i.e., yearlings were not captured in proportion to their availability). This explanation seems questionable for 2 reasons. First, all 3 statcs used similar techniques for capturing horses; therefore, any sampling bias associated with the capture technique should also be present in data from Nevada and Wyoming. Second, yearlings are not spatially or socially segregated in horse populations, but usually are associated with harems or bands of stallions (Berger 1986). The normal procedure when capturing horses was to consolidate several of these social groups and herd them as a unit into a corral
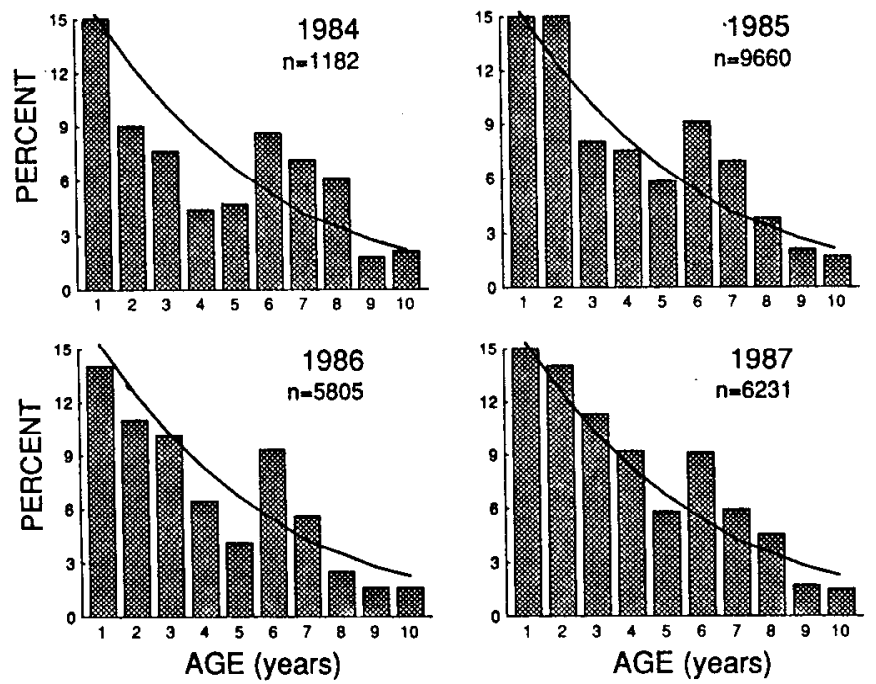

Fig. 1. Age distributions of feral horses removed from public lands in Nevada during 4 consecutive years. The line represents the expected stable age distribution derived from the $S 1$ survival and $F 2$ fecundity schedules presented by Garrott et al. (1991).

trap. Thus, there was no obvious mechanism that would make yearlings less susceptible to capture.

An alternative explanation for the deficiency of yearlings in these Oregon data is the systematic misclassification of yearlings into adjacent age classes. Discussions with Oregon BLM personnel revealed that horses were considered yearlings if the third deciduous incisors were partially erupted, but if these incisors were fully 
erupted and in contact with opposing teeth, the animal was considered a 2-year-old. The third incisors, however, are in contact by 18-20 months of age (Ensminger 1977, Amer. Assoc. Equine Practitioners 1981). Hence, yearlings aged in late autumn or winter, the primary capture period, may have been misclassified as 2-yearolds. This supposition is supported by the large 2-year-old cohort in the Oregon data.

The most reasonable explanation for the preponderance of horses assigned into the 6-and 7-year age groups is the misclassification of animals from adjacent age classes into the 6-and 7-year age groups. Caughley $(1965,1977)$ demonstrated considerable variation in the timing of tooth eruption and wear patterns between individual Himalayan thar (Hemitragus jemlahicus). Similar variation probably exists in other large herbivores as well. This variation would result in errors in estimating age of animals that can best be visualized as a probability distribution. An animal that is $X$ years old may have $a .50$ probability of being assigned into the correct age class based on dental characteristics, a 0.20 probability of being assigned into either the $X-1$ or $X+1$ age classes, and a 0.05 probability of being assigned into either the $X-2$ or $X+2$ age classes. For example, some 5-year-old animals will have greater than normal incisor wear and be classified as 6-year-olds, whereas, incisors of some 6-year-olds will have less than normal wear and be classified as 5-year-olds. These errors obviously are not compensating in the first several age classes that use incisor wear to estimate age. There is a tendency for 4- and 5-year-old age classes to be under represented in the data when compared to the expected distribution (Table 1, Fig. 1), suggesting these animals may be the source for the overabundance of 6-and 7-year olds. The reason for this is uncertain, but it is clear from data in Table 1 and Figure 1 that aging errors were common and a distinct bias exists in these age classes.

The American Association of Equine Practitioners (1981) cautions that after all permanent teeth are fully erupted, aging becomes increasing difficult and Ensminger (1977) states that horses cannot be accurately aged beyond 12 years. The age distributions from both Nevada and Oregon, where horses were assigned ages up to 30 years, provides evidence that aging older animals is quite speculative.

Given the uncertainties of the current aging criteria, caution should be exercised when developing age-specific demographic variables based on incisor eruption and wear. With the exception of the yearling age class in Oregon, no consistent biases were detected in the 0- to 4-year age classes, therefore, development of survival and fecundity rates based on yearly increments appears reasonable. These age classes are of particular significance in assessing age of first reproduction, since this is an important parameter in population models of long-lived mammals (Eberhardt 1985). Results of this study suggests that beyond age 4 it would be judicious to group horses into broader age classes such as $5-9,10-14,15-19$, and $\geq 20$. Such general age classes would not adversely affect the development of age-specific survival and fecundity schedules because both survival and fecundity of large mammals remains relatively constant after animals become mature until the onset of senescence in the oldest age classes (Eberhardt 1985). Future research on estimating ages of feral horses that could be useful would include comparing age estimates based on tooth eruption and wear with known-age animals and ages based on tooth cementum structures.

\section{Literature Cited}

American Association of Equine Practitioners. 1981. Official guide for determining the age of horse. Amer. Assoc. Equine Practitioners, Golden, Colo.

Berger, J. 1986. Wild horses of the Great Basin. Univ. Chicago Press, Chicago, Ill.

Caughley, G. 1965. Horn rings and tooth eruption as criteria of age in Himalayan thar, Hemitragus jemlahicus. New Zealand J. Sci. 8:333-351.

Caughley, G. 1977. Analysis of vertebrate populations. John Wiley and Sons, N.Y.

Cooke, J.G., and W.K. de la Mare. 1983. The effects of variability in age data on the estimation of biological parameters of minke whales (Balaenoptera acutorostrata). Rep. Int. Whaling Comm. 33:333-338.

Dapson, R.W. 1980. Guidelines for statistical usage in age-estimation technics. J. Wildl. Manage. 44:541-548.

de la Mare, W.K., and J.G. Cooke. 1984. Some further effects of error in age determination of the estimation of demographic parameters of whales. Rep. Int. Whaling Comm. 34:711-715.

Eberhardt, L.L., A.K. Majorowicz, and J.A. Wilcox. 1982. Apparent rates of increase for two feral horse herds. J. Wildl. Manage. 46:367-374.

Eberhardt, L.L. 1985. Assessing the dynamics of wild populations. J. Wildl. Manage. 49:997-1012.

Ensminger, M.E. 1977. Horses and horsemanship. Interstate Printers and Publ., Inc., Danville, Ill.

Fatti, L.P., G.L. Smuts, A.M. Starfield, and A.A. Spurdle. 1980. Age determination in African elephants. J. Mamm. 61:547-551.

Garrott, R.A. 1991. Feral horse fertility control: potential and limitations. Wildl. Soc. Bull. 19:52-58.

Garrott, R.A., and L. Taylor. 1990. Population dynamics of a feral horse population in Montana. J. Wildl. Manage. 54:604-612.

Garrott, R.A., T.C. Eagle, and E.D. Plotka. 1991a. Age-specific reproduction in feral horses. Can. J. Zool. 69:

Garrott, R.A., D.B. Siniff, and L.L. Eberhardt. 1991b. Growth rates of feral horse populations. J. Wildl. Manage. In. Press.

National Research Council. 1980. Wild and free-roaming horses and burros: Current knowledge and recommended research. Nat. Acad. Press, Washington, D.C.

National Research Council. 1982. Wild and free-roaming horses and burros: Final report. Nat. Acad. Press, Washington, D.C.

Plotka, E.D., T.C. Eagle, S.J. Gaulke, J.R. Tester, and D.B. Siniff. 1988. Hematologic and blood chemical characteristics of feral horses from three management areas. J. Wildl. Diseases 24:231-239.

Seal, U.S., and E.D. Plotka. 1983. Age-specific pregnancy rates in feral horses. J. Wildl. Manage. 47:422-429.

Siler, W. 1979. A competing-risk model for animal mortality. Ecol. 60:750-757.

Siniff, D.B., J.R. Tester, and G.L. McMahon. 1986. Foaling rate and survival of feral horses in western Nevada. J. Range Manage. 39:296-297.

Starfield, A.M., and A.L. Bleloch. 1986. Building models for conservation and wildlife management. Macmillan Publ. Co., N.Y.

Wolfe, M.L., Jr. 1980. Feral horse demography: a preliminary report. J. Range Manage. 33:354-360. 